\title{
FOXO3a inhibits nephroblastoma cell proliferation, migration and invasion, and induces apoptosis through downregulating the Wnt/ $\beta$-catenin signaling pathway
}

\author{
CHENG QIAN $^{1}$ and QIANG LIU ${ }^{2}$ \\ ${ }^{1}$ Department of Pediatric Surgery, Zaozhuang Municipal Hospital, Zaozhuang, Shandong 277102; \\ ${ }^{2}$ Department of Urinary Surgery, The Second People's Hospital of Nantong, Nantong, Jiangsu 226002, P.R. China
}

Received April 10,2020; Accepted June 26, 2020

DOI: $10.3892 / \mathrm{mmr} .2021 .12436$

\begin{abstract}
Forkhead transcription factor O subfamily $3 \mathrm{~A}$ (FOXO3a) is an important tumor suppressor gene that is expressed in renal tissue and has been reported to be downregulated in clear cell renal cell carcinoma (CCRCC). Notably, the overexpression of FOXO3a was previously discovered to inhibit the progression of CCRCC. However, the expression levels of FOXO3a in nephroblastoma cell lines remain unknown. The present study aimed to investigate the expression levels of FOXO3a in nephroblastoma cell lines and to determine the mechanism of action of the biological functions of FOXO3a. Western blotting and reverse transcription-quantitative PCR were used to analyze the expression levels of FOXO3a in nephroblastoma cell lines. Subsequently, the effects of the overexpression of FOXO3a and the genetic knockdown of the Wnt $/ \beta$-catenin signaling protein Axin- 2 on the biological functions were determined through Cell Counting Kit-8, cell colony formation assays, scratch and Transwell assay and flow cytometric analysis experiments. The expression levels of FOXO3a were discovered to be downregulated in nephroblastoma cell lines. The overexpression of FOXO3a inhibited the proliferation, invasion and migration of nephroblastoma cells, while inducing apoptosis. Furthermore, the overexpression of FOXO3a downregulated the expression levels of $\beta$-catenin and Cyclin-D1 proteins involved in the $\mathrm{Wnt} / \beta$-catenin signaling pathway. Cell proliferation and the migration and invasion ability of 17-94 cells in shRNA-Axin2-2 group were promoted. Cell apoptosis was predominantly increased by overexpressed FOXO3a, which was reversed by shRNA-Axin2-1. The biological effects of overexpressing FOXO3a on nephroblastoma
\end{abstract}

Correspondence to: Dr Qiang Liu, Department of Urinary Surgery, The Second People's Hospital of Nantong, 298 Xinhua Road, Nantong, Jiangsu 226002, P.R. China

E-mail: qiang1413@yeah.net

Key words: forkhead transcription factor $\mathrm{O}$ subfamily $3 \mathrm{~A}$, nephroblastoma, Wnt $/ \beta$-catenin signaling pathway, proliferation, apoptosis were reversed after activation of $\mathrm{Wnt} / \beta$-catenin. In conclusion, the findings of the present study suggested that FOXO3a may inhibit nephroblastoma cell proliferation, migration and invasion, while inducing apoptosis, by downregulating the Wnt/ $\beta$-catenin signaling pathway. These results may provide a novel method for the early diagnosis and precise treatment of nephroblastoma.

\section{Introduction}

Wilms tumor, also known as nephroblastoma, is the most common type of renal malignancy diagnosed in children (1-3). In the past few years, the treatment of nephroblastoma has significantly improved following the application of various treatment regimens and techniques, including surgery, radiotherapy, chemotherapy and autologous stem cell transplantation (4). Thus, nephroblastoma is one of the most successful types of pediatric malignant tumor in terms of prognosis (5). At present, the 5-year survival rate of patients with nephroblastoma has reached $90 \%$, but there remains $10 \%$ of children who die due to recurrence, metastasis and insensitivity to chemotherapy drugs (6-7). However, the current understanding of the pathogenesis and metastatic mechanism of action of nephroblastoma is insufficient, and corresponding effective targeted treatments are lacking. Therefore, current clinical research is focused on investigating more effective targeted treatments for nephroblastoma to reduce its metastatic and recurrence rate.

The forkhead transcription factor O (FOXO) family, also named FKHR, consists of four subtypes: FOXO1/FKHR/ FOXO subfamily 1a (FOXO1a), FOXO3/FKHRL1/FOXO3a, FOXO4/AFX and FOXO6, which have similar structures, functions and regulatory mechanisms (8). FOXOs are an essential protein family that have been discovered to regulate cell apoptosis, the cell cycle, DNA damage repair, oxidative stress, energy metabolism and longevity, and cancer development, amongst other cell functions (9-11). In particular, FOXO3a is a tumor suppressor gene belonging to the FOXO family (12), which has been reported to control various signaling pathways and biological processes of tumor cells. FOXO3a can inhibit the invasion of breast cancer cells by activating ER- $\alpha$ signaling pathway (13). The low expression of FOXO3a may promote 
the invasion and migration of non-small cell lung cancer cells through PI3K/Akt signaling pathway (14). It was found that FOXO3a can induce EMT and promote the metastasis of renal cancer cell (15).

Downregulated expression levels of FOXO3a have been discovered to be associated with the occurrence, progression and drug resistance of breast, pancreatic, liver and bladder cancer, amongst other types of tumor (16-18). Notably, it has been reported that FOXO3a may exert an antitumor effect in breast cancer, non-small cell lung cancer and renal cancer (19).

The Wnt and PI3K/AKT signaling pathways are reported to be closely related to the development of nephroblastoma (20). AKT serves an important role in a variety of interrelated cellular signaling mechanisms involved in cellular metabolism, growth and division, the inhibition of apoptosis and angiogenesis $(21,22)$. The activation of $\mathrm{Wnt} / \beta$-Catenin has been identified to have a crucial role in tumor development $(23,24)$. $\beta$-catenin is a multifunctional protein, which has not only been discovered to serve as the main structural component of cell adhesion, but also to participate in embryogenesis and tumor formation (25). However, to the best of our knowledge, the relationship between nephroblastoma and the Wnt signaling pathway remains poorly understood, and the biological role and pathogenic mechanism of the Wnt signaling pathway in the development of nephroblastoma has not been reported. Since nephroblastoma is an embryonic renal tumor, abnormalities during renal development have been identified to be closely associated with its occurrence (26). As the Wnt signaling pathway is an important signaling transduction pathway involved in the process of renal development (27-29), it may be of great significance to investigate the influence of the abnormalities in the Wnt signaling pathway in association with the occurrence of nephroblastoma.

The present study aimed to analyze the expression levels of FOXO3a in nephroblastoma and to determine the role of FOXO3a in the proliferation, migration and invasion of nephroblastoma. The results suggested that FOXO3a may regulate the $\mathrm{Wnt} / \beta$-catenin signaling pathway to inhibit nephroblastoma progression, thus providing a potential, novel therapeutic target for the treatment of the disease.

\section{Materials and methods}

Cell culture and transfection. The normal human renal cell line (HK-2) and nephroblastoma cell lines (17-94, AG01615, HFWT, WILTU-1 and WIT49) were obtained from the American Type Culture Collection. Cells were cultured in DMEM (Gibco; Thermo Fisher Scientific, Inc.), supplemented with $10 \%$ FBS (Gibco; Thermo Fisher Scientific, Inc.) and 1\% penicillin-streptomycin, and maintained at $37^{\circ} \mathrm{C}$ in an humidified atmosphere of $5 \% \mathrm{CO}_{2}$.

For cell transfection, $1 \times 10^{5} 17-94$ cells/well were plated into six-well plates and transfected with overexpression (OE)-FOXO3a, overexpression (OE)-NC, short hairpin RNA (shRNA)-targeting Axin-2 (shRNA-Axin-2-1 and shRNA-Axin-2-2) and shRNA-NC (100 nM) were using Lipofectamine $^{\circledR} 2000$ (Invitrogen; Thermo Fisher Scientific, Inc.), according to manufacturer's protocol. All plasmids were supplied from Guangzhou RiboBio Co., Ltd. Subsequent experiments were performed $48 \mathrm{~h}$ after transfection.
Cell Counting Kit-8 (CCK-8) assay. A total of $5 \times 10^{3}$ 17-94 cells/well were plated into 96 -well plates. Following 24,48 or $72 \mathrm{~h}$ of incubation at $37^{\circ} \mathrm{C}$, a CCK-8 kit (Dojindo Molecular Technologies, Inc.) was used to analyze the proliferative capacity/cell viability of transfected 17-94 cells, according to manufacturer's protocol. Briefly, $10 \mu \mathrm{l} \mathrm{CCK}-8$ reagent was added/well and incubated for $1 \mathrm{~h}$ at $37^{\circ} \mathrm{C}$. The absorbance was subsequently measured at a wavelength of $450 \mathrm{~nm}$ using a microplate reader.

Colony formation assay. Following $48 \mathrm{~h}$ of transfection at $37^{\circ} \mathrm{C}, 800$ cells were seeded into 6 -well plates and incubated at $37^{\circ} \mathrm{C}$ in complete medium for 21 days with the medium changed every 3 days. Following the incubation at $37^{\circ} \mathrm{C}$, these cells were fixed with the $70 \%$ ethanol solution and the plates were stained with $0.5 \%$ crystal violet at room temperature for 20 min. (Santa Cruz Biotechnology, Inc.).

Wound healing assay. A total of 5x105 17-94 cells/well were plated into six-well plates and cultured until $100 \%$ confluence in complete medium at $37^{\circ} \mathrm{C}$. Subsequently, the monolayer of cells was scratched by a sterilized pipette tip $(20 \mu \mathrm{l})$ and the cells were incubated in serum-free DMEM for $24 \mathrm{~h}$ at $37^{\circ} \mathrm{C}$. The migratory distance of the cells was observed under a light microscope (magnification, x200; Olympus Corporation) at $0 \mathrm{~h}$ (and the scratch width is recorded as W0.) and $24 \mathrm{~h}$ (the scratch width was recorded as W24), and analyzed using ImageJ version 1.49 software (National Institutes of Health). The migration rate was calculated as Migration rate $=\left(\mathrm{W}_{24}-\mathrm{W}_{0}\right) / \mathrm{W}_{0} \mathrm{x} 100 \%$.

Transwell Matrigel assay. A total of $1 \times 10^{4}$ cells/well were plated into the upper chambers of 24-well Transwell plates (8.0- $\mu \mathrm{m}$ PET membrane; Corning, Inc.) in $400 \mu 1$ serum-free DMEM. The membranes were precoated with Matrigel at $37^{\circ} \mathrm{C}$ for $2 \mathrm{~h}$. The lower chambers were filled with $600 \mu \mathrm{l}$ DMEM supplemented with $10 \%$ FBS. Following incubation for $24 \mathrm{~h}$ at $37^{\circ} \mathrm{C}$, the cells on the bottom of the lower chamber were fixed with $90 \%$ ethanol solution for $30 \mathrm{~min}$ at $37^{\circ} \mathrm{C}$ and stained with $0.1 \%$ crystal violet for $10 \mathrm{~min}$ at room temperature. The invasive cells were visualized using a light microscope (Olympus FV500; Olympus Corporation, magnification, x200) and analyzed using ImageJ version 1.49 software (National Institutes of health).

Flow cytometric analysis of apoptosis. The rate of cell apoptosis was analyzed using an Annexin V-FITC/propidium iodide (PI) flow cytometry assay kit (BD Biosciences), according to the manufacturer's protocol. Briefly, cells were centrifuged at $\sim 200 \mathrm{x}$ g for 3-5 min for precipitation and collection, then fixed in precooled $70 \%$ ethanol at $4^{\circ} \mathrm{C}$ overnight. The cells were then resuspended in $300 \mu \mathrm{l}$ cold binding buffer and incubated with $5 \mu \mathrm{l}$ Annexin V-FITC for $10 \mathrm{~min}$ in the dark at room temperature. Following the addition of $5 \mu \mathrm{l} \mathrm{PI}$ and $200 \mu \mathrm{l}$ binding buffer, the samples were incubated in the dark at room temperature for a further $5 \mathrm{~min}$. Apoptotic cells were subsequently analyzed using the FACSCalibur flow cytometer (BD Biosciences) and data were analyzed using BD Accuri C6 (BD Biosciences). The percentage of early and late apoptotic cells was calculated. The experiments were independently repeated 3 times. 
Reverse transcription-quantitative PCR (RT-qPCR). Total RNA was extracted from 17-94 cells using TRIzol ${ }^{\circledR}$ reagent (Invitrogen; Thermo Fisher Scientific, Inc.) at $-40^{\circ} \mathrm{C}$. Total RNA was reverse transcribed into cDNA using the TaqMan Reverse Transcription kit (Takara Bio, Inc.), according to the manufacturer's protocol. qPCR was subsequently performed using a SYBR Taq kit (Roche Diagnostics) to detect the relative expression of FOXO3a and AXIN2 on an a Bi 7500 real-Time PCR system (Applied Biosystems; Thermo Fisher Scientific, Inc.). The following thermocycling conditions were used for the qPCR: $95^{\circ} \mathrm{C}$ for $30 \mathrm{sec}$, followed by 40 cycles of $95^{\circ} \mathrm{C}$ for $5 \mathrm{sec}$ and $60^{\circ} \mathrm{C}$ for $30 \mathrm{sec}$. Primers were FOXO3a, forward, 5'-CGGACAAACGGCTCACTCT-3' and reverse, 5'-GGA CCCGCATGAATCGACTAT-3'; $\beta$-actin, forward, 5'-ATC ACCATTGGCAATGAGCG-3' and reverse, 5'-TTGAAGGTA GTTTCGTGGAT-3'; AXIN2, forward, 5'-CACGGAAAC TGTTGACAGTGGATAC-3' and reverse, 5'-GGTGGCTGG TGCAAAGACATAG-3'; GAPDH, forward, 5'-GCACCGTCA AGGCTGAGAAC-3' and reverse, 5'-GTGA AGACGCCA GTGGA-3'. Gene expression levels were then normalized to that of GAPDH, whereas fold changes were calculated using the $2^{-\Delta \Delta \mathrm{Cq}}$ method (30).

Western blotting. Total protein was extracted from 17-94 cells using RIPA lysis buffer (Beyotime Institute of Biotechnology) with protease inhibitors (Roche Diagnostics). Total protein was quantified using a bicinchoninic acid assay kit (Beyotime Institute of Biotechnology) and $30 \mu \mathrm{g}$ protein/lane was separated using 10\% SDS-PAGE. The proteins were subsequently transferred onto PVDF membranes (EMD Millipore) and blocked with 5\% non-fat milk for $2 \mathrm{~h}$ at room temperature. The membranes were then incubated overnight at $4^{\circ} \mathrm{C}$ with the following primary antibodies: Anti-FOXO3A (1:5,000; cat. no. ab109629; Abcam); anti-MMP2 (1:4,000; cat. no. ab92536; Abcam); anti-MMP9 (1:10,000; cat. no. ab76003; Abcam); anti-MMP13 (1:1,000; cat. no. ab51072; Abcam); anti-Caspase-3 (1:500; cat. no. ab13847; Abcam); anti-Bim (1:1,000; cat. no. ab32158; Abcam); anti- $\beta$ Catenin (1:1,000; cat. no. ab16051; Abcam); Rabbit anti-Cyclin D1 (1:200; cat. no. ab16663; Abcam); anti-Axin 2 (1:500; cat. no. ab32197; Abcam); Anti-Bcl-2 (1:1,000; cat. no. 3498; Cell Signaling Technology, Inc.), anti-Bax (1:1,000; cat. no. 5023; Cell Signaling Technology, Inc.), anti-cleaved-caspase-3 (1:500; cat. no. 9661; Cell Signaling Technology, Inc.) and anti-GAPDH (1:2,000; cat. no. MAB374; EMD Millipore). Following the primary antibody incubation, the membranes were incubated with horseradish peroxidase (HRP)-conjugated anti-rabbit (1:10,000; cat. no. sc-2357; Santa Cruz Biotechnology, Inc.) secondary antibodies at room temperature for $2 \mathrm{~h}$. Densitometric analysis was performed using ImageJ software (version 1.49; National Institutes of Health). Protein bands were detected using an ECL detection reagent (EMD Millipore) and protein expression levels were normalized to GAPDH. The experiments were performed in triplicate.

Statistical analysis. All data are presented as the mean \pm SEM and all experiments were repeated three times. Statistical analysis was performed using GraphPad 6.0 software (GraphPad Software, Inc). Statistical differences among groups were determined using a one-way ANOVA followed by a Tukey's or Dunnett's post hoc test. $\mathrm{P}<0.05$ was considered to indicate a statistically significant difference.

\section{Results}

FOXO3a expression levels are significantly downregulated in nephroblastoma cells. To investigate the expression levels of FOXO3a in nephroblastoma cells, 17-94, AG01615, HFWT, WILTU-1 and WIT49, and the normal kidney cell HK-2, RT-qPCR and western blotting were performed. The expression levels of FOXO3a were significantly downregulated at both the mRNA and protein level in nephroblastoma cells compared with the normal kidney HK-2 cells (Fig. 1A-C). The expression levels of FOXO3a in 17-94 cells were downregulated the most, thus, 17-94 cells were used for subsequent experiments.

Overexpression of $\mathrm{FOXO3a}$ inhibits nephroblastoma cell proliferation, cell invasion and migration. To determine the role of FOXO3a in nephroblastoma cells, OE-FOXO3a and OE-NC plasmids were transfected into 17-94 cells. The results of the RT-qPCR and western blotting demonstrated that the OE-FOXO3a plasmid was successfully transfected into 17-94 cells; the expression levels of FOXO3a were significantly upregulated in the OE-FOXO3a group compared with the control and OE-NC groups (Fig. 1D-F). The results of the CCK-8 assay indicated that the cell proliferation rate was significantly reduced in 17-94 cells transfected with the OE-FOXO3a plasmid compared with the control and OE-NC groups (Fig. 1G). Similar results were observed in the colony formation abilities of 17-94 cells (Fig. 1H). Furthermore, the overexpression of FOXO3a significantly reduced the invasive and migratory abilities of 17-94 cells compared with the OE-NC and control groups (Fig. 2A-D). Western blotting results also indicated that the overexpression of FOXO3a significantly downregulated the expression levels of the invasion and migration-related proteins, matrix metalloproteinase (MMP)2, MMP9 and MMP13 in 17-94 cells compared with the control and OE-NC groups (Fig. 2E).

Overexpression of $\mathrm{FOXO} 3$ a promotes nephroblastoma cell apoptosis. Flow cytometric analysis was used to detect the rate of cell apoptosis. The apoptotic rate was significantly increased in the 17-94 cells overexpressing FOXO3a compared with the control and OE-NC groups (Fig. 3A and B). To further verify the role of FOXO3a in cell apoptosis, western blotting was used to detect the expression levels of the apoptosis-related proteins, Bax, Bcl-2, Bim, cleaved caspase-3 and caspase-3. The results revealed that the protein expression levels of Bax, Bim and cleaved caspase-3 were significantly upregulated, while those of the $\mathrm{Bcl}-2$ protein were significantly downregulated in the OE-FOXO3a group compared with the control and OE-NC groups (Fig. 3C).

FOXO3a-induced suppression over cell proliferation, migration and invasion is regulated by Wnt/ $\beta$-catenin signaling. To further investigate whether FOXO3a regulated cell viability, migration and invasion by activating Wnt/ $\beta$-catenin signaling, western blotting was used to 
A

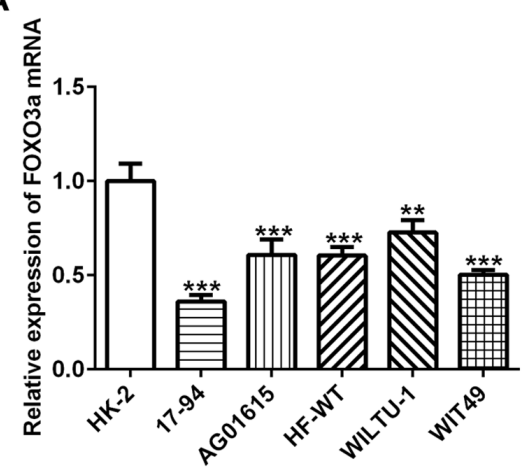

D

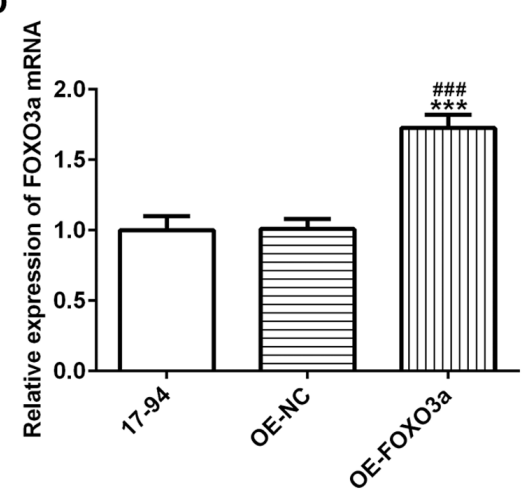

G

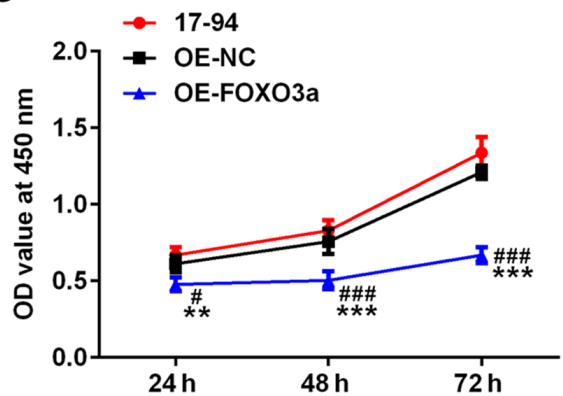

B

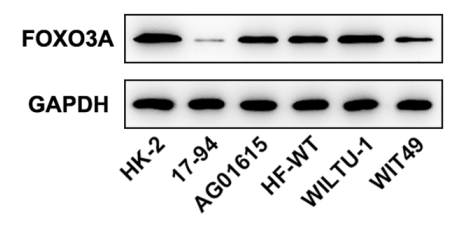

E

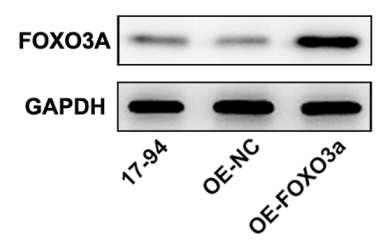

C

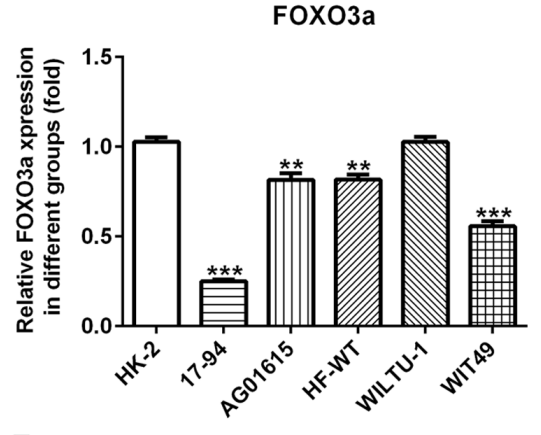

F

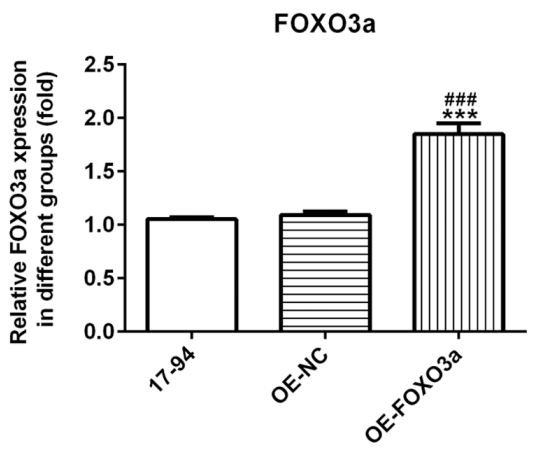

H
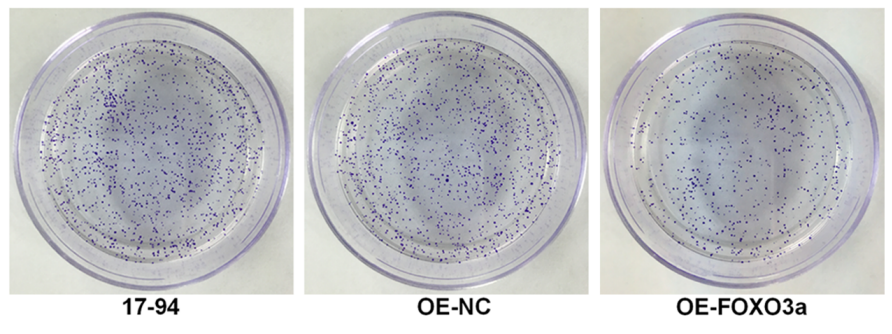

Figure 1. Overexpression of FOXO3a inhibits the proliferation of nephroblastoma cells. Expression levels of FOXO3a in nephroblastoma cell lines (17-94, AG01615, HFWT, WILTU-1 and WIT49) and the normal kidney cell line HK-2 were analyzed using (A) RT-qPCR and (B) western blotting. (C) Semi-quantification of the expression levels of FOXO3a presented in part (B). ${ }^{* *} \mathrm{P}<0.01,{ }^{* * * *} \mathrm{P}<0.001$ vs. HK-2. Effect of OE-FOXO3a on the expression levels of FOXO3a in 17-94 cells was determined using (D) RT-qPCR and (E) western blotting. (F) Semi-quantification of the expression levels of FOXO3a from part (E). (G) Cell Counting Kit-8 assay was used to determine that OE-FOXO3a-transfected 17-94 cells had significantly decreased rates of cell proliferation. (H) OE-FOXO3a-transfected 17-94 cells demonstrated decreased rates of colony formation. ${ }^{* * *} \mathrm{P}<0.01,{ }^{* * *} \mathrm{P}<0.001$ vs. control; ${ }^{\# P} \mathrm{P}<0.01,{ }^{\# \# \#} \mathrm{P}<0.001$ vs. OE-NC. $n=3$. FOXO3a, forkhead transcription factor O subfamily $3 \mathrm{~A}$; OE, overexpression; NC, negative control; RT-qPCR, reverse transcription-quantitative PCR; OD, optical density.

analyze the expression levels of the $\mathrm{Wnt} / \beta$-catenin signaling pathway-related proteins, Axin-2, $\beta$-catenin and cyclin D1. The results identified that the overexpression of FOXO3a significantly upregulated the protein expression levels of Axin-2, while the protein expression levels of $\beta$-catenin and cyclin D1 were significantly downregulated, compared with the control and OE-NC groups (Fig. 4A). The transfection efficiency of shRNA-Axin-2-1 and shRNA-Axin-2-2 was analyzed using western blotting and RT-qPCR; the results demonstrated that the inhibitory effect of shRNA-Axin-2-1 on the Axin-2 expression levels was superior compared with shRNA-Axin-2-2 in 17-94 cells, thus shRNA-Axin-2-1 was chosen for subsequent experiments (Fig. 4B and C).

Subsequently, OE-FOXO3a and shRNA-Axin-2 were co-transfected into 17-94 cell lines. The CCK-8 assay revealed that the cell viability of 17-94 cells was significantly increased in the OE-FOXO3a + shRNA-Axin-2 group compared with the OE-FOXO3a and OE-FOXO3a + shRNA-NC groups (Fig. 4D). Furthermore, similar results were recorded in the colony formation ability of 17-94 cells (Fig. 4E). Taken together, these findings suggested that the activation of Wnt/ $\beta$-catenin signaling may reverse the FOXO3a overexpression-induced inhibition of cell viability and proliferation in nephroblastoma.

The migratory and invasive abilities of 17-94 cells in the OE-FOXO3a + shRNA-Axin-2 group were significantly increased compared with the OE-FOXO3a and OE-FOXO3a + shRNA-NC groups (Fig. 5A-D). In addition, western blotting was used to analyze the expression levels of the invasion and migration-related proteins, MMP2, MMP9 and MMP13. Compared with the OE-FOXO3a and OE-FOXO3a + shRNA-NC groups, significantly upregulated expression levels of MMP2, MMP9 and MMP13 were observed in the OE-FOXO3a + shRNA-Axin-2 group (Fig. 5E). 
A
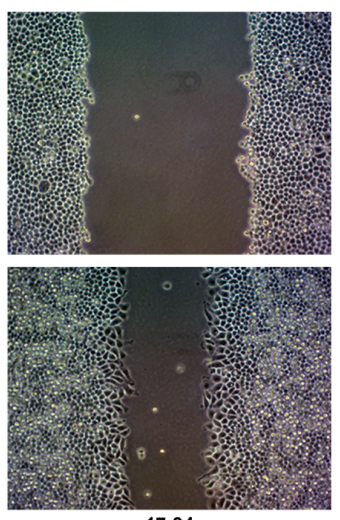

$17-94$

C

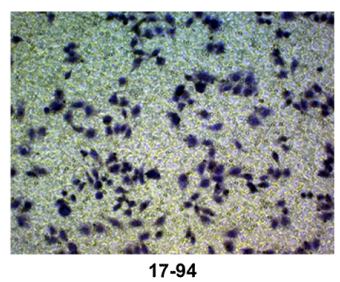

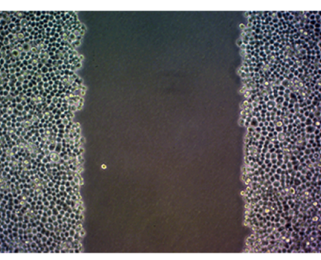

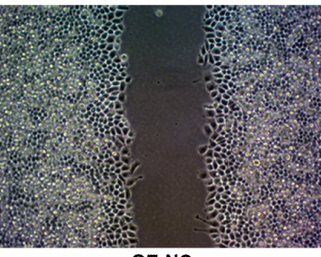

OE-NC

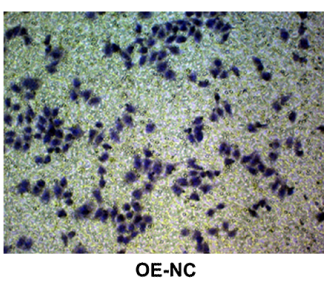

OE-NC

E

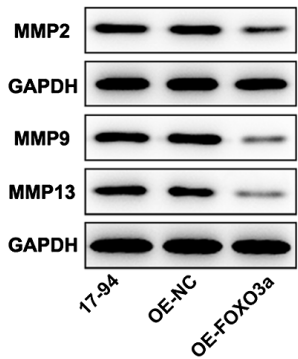

MMP2

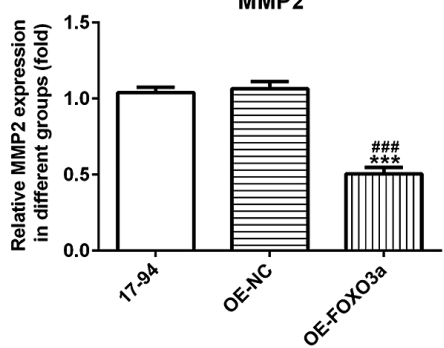

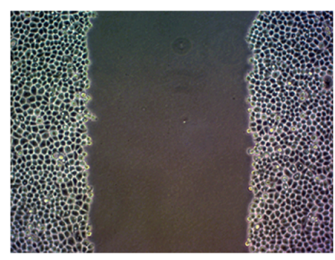

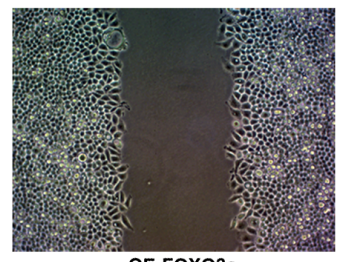

OE-FOXO3a

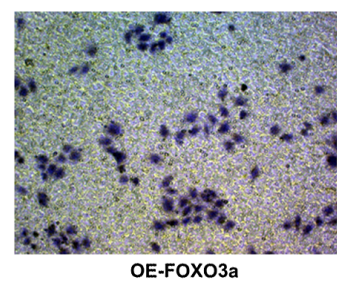

B
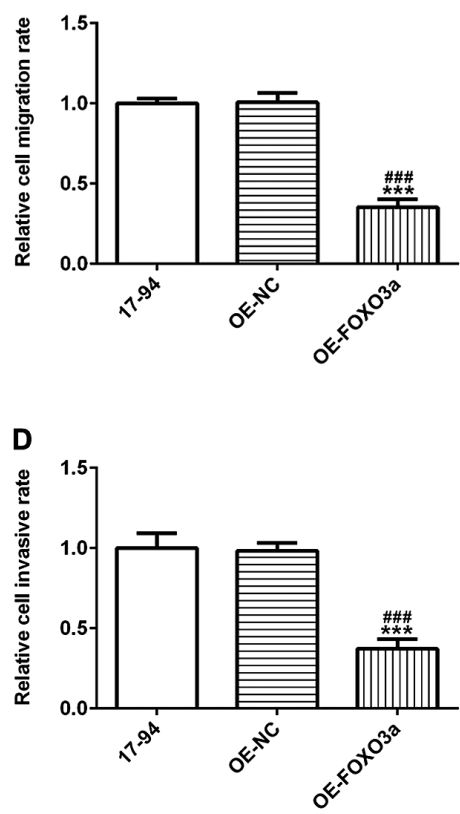

MMP13
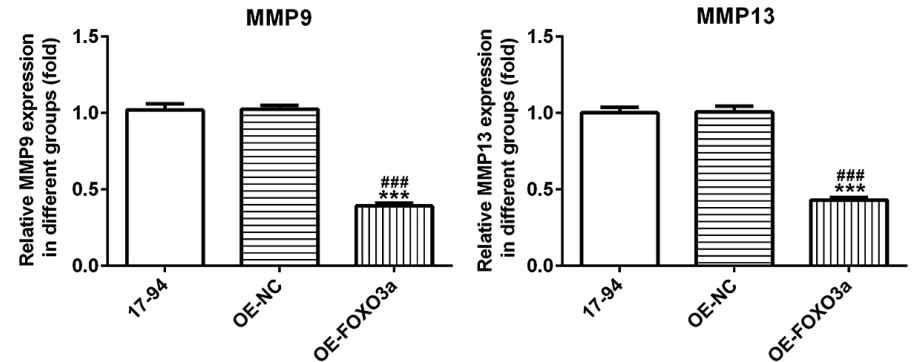

Figure 2. Overexpression of FOXO3a inhibits the invasion and migration of nephroblastoma cells. (A) Wound healing assay was used to determine the migratory ability of OE-FOXO3a-transfected cells (magnification, x200). (B) Semi-quantification of the cell migration rate in part (A). (C) Transwell Matrigel assays were used to determine the invasive ability of OE-FOXO3a-transfected cells (magnification, x200). (D) Semi-quantification of the cell invasive rate from part (C). (E) Western blotting was performed to analyze the protein expression levels of MMP2, MMP9 and MMP13 in OE-FOXO3a-transfected cells. ${ }^{* * * *} \mathrm{P}<0.001$ vs. control;

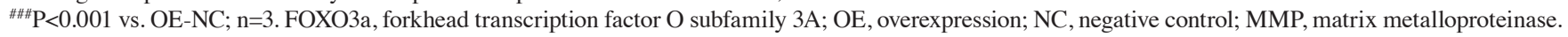

FOXO3a-induced cell apoptosis is regulated by Wnt/ $\beta$-catenin signaling. 17-94 cells were co-transfected with OE-FOXO3a and shRNA-Axin-2 and flow cytometry was used to determine the rate of cell apoptosis. Compared with the OE-FOXO3a + shRNA-NC and OE-FOXO3a groups, the cell apoptotic rate was significantly decreased in the OE-FOXO3a + shRNA-Axin-2 group (Fig. 6A and B). Furthermore, western blotting was performed to analyze the expression levels of the apoptosis-related proteins, Bax, Bcl-2, Bim, cleaved caspase-3 and caspase- 3 . The results revealed that the upregulated expression levels of Bax, Bim and cleaved caspase-3, and downregulated expression levels of $\mathrm{Bcl}-2$, induced by $\mathrm{OE}-\mathrm{FOXO} 3 \mathrm{a}$ were significantly reversed following the co-transfection with OE-FOXO3a and shRNA-Axin-2 (Fig. 6C).

\section{Discussion}

Over the past few years, the incidence of childhood tumors has increased significantly (31). Renal cancer is the most type of common malignant tumor to occur in children, accounting for $7 \%$ of childhood cancers (32). The most common pathological type of renal cell carcinoma in children is nephroblastoma (2).
The rare pathological types include rhabdomyoma sarcoma, clear cell sarcoma, congenital mesodermal nephroma, renal Ewing's sarcoma, primary renal myoepithelial carcinoma, cystic partially differentiated nephroblastoma, multilocular cystic nephroma, primary synovial sarcoma and anaplastic sarcoma (2,31-33). Nephroblastoma has been discovered to affect the function of unilateral or bilateral kidneys $(33,34)$. Although the diagnosis and treatment of nephroblastoma has significantly improved, the mortality rate of nephroblastoma in children remains high $(10.7 \%)(35,36)$. Thus, studying the effects of factors related to early nephroblastoma may provide a novel target and treatment method for nephroblastoma.

FOXO3a is a member of the FOXO family; it enters the nucleus after binding with $\beta$-catenin, where it was reported to accelerate the self-renewal of cancer cells, thus promoting the formation of tumors $(37,38)$. FOXO3a has also been discovered to combine with the transcription regulatory machinery of different target genes in the nucleus to serve a role in transcriptional regulation, in addition to participating in the proliferation, migration, invasion and apoptosis of cells $(12,39)$. FOXO3a was also discovered to serve a role in abnormal activity, stress tolerance and the metabolic homeostasis of 


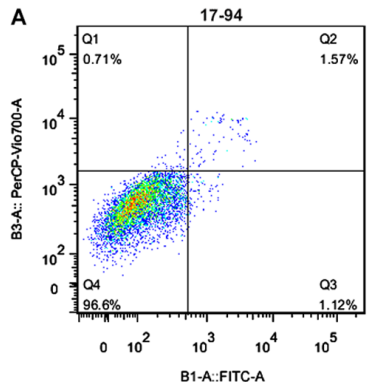

C

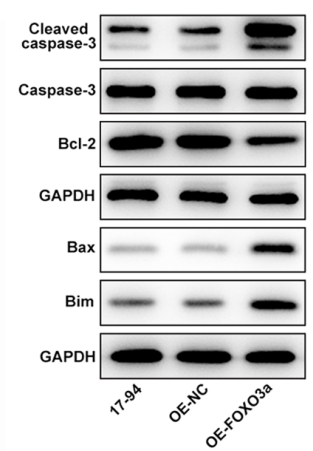

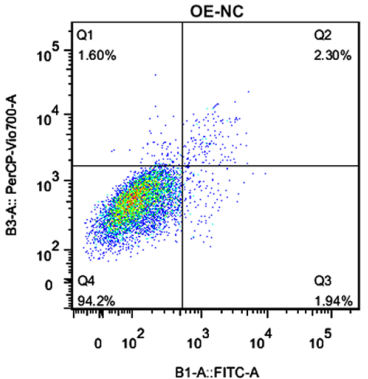
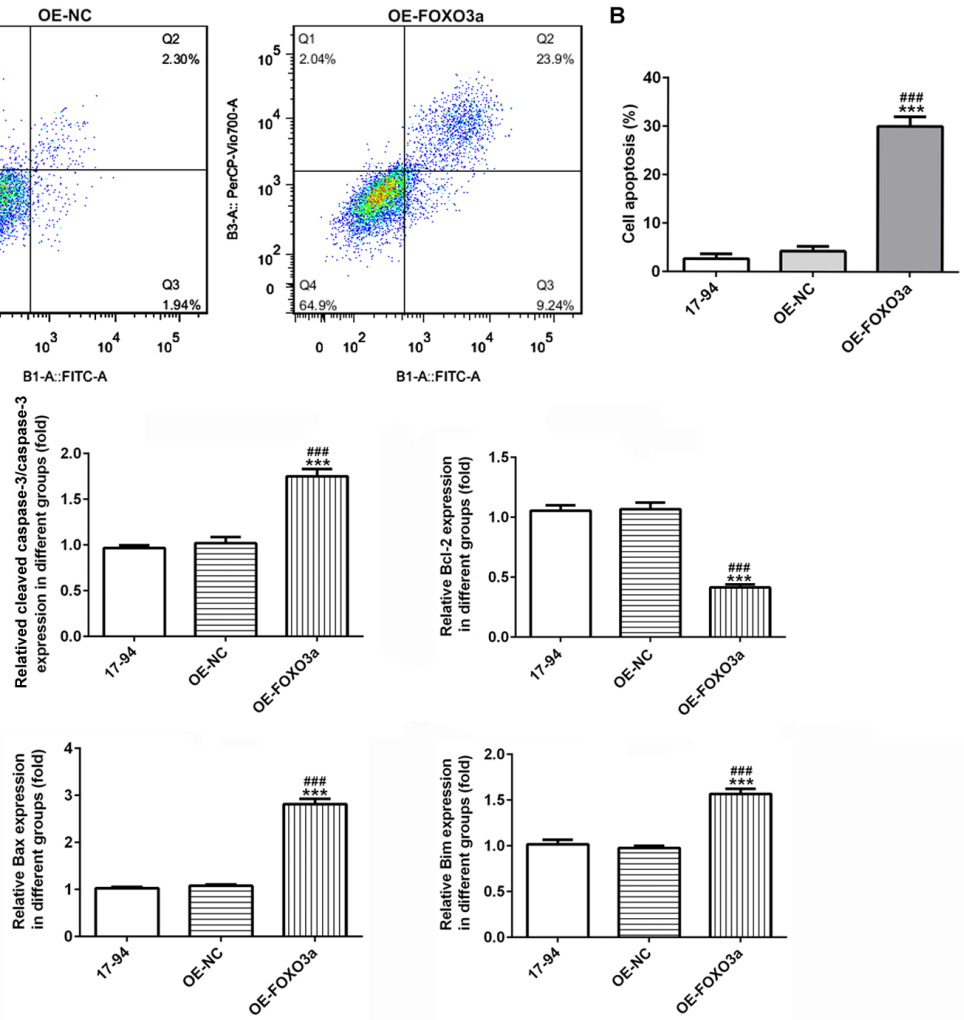

Figure 3. Overexpression of FOXO3a promotes cell apoptosis in nephroblastoma cells. (A) Flow cytometric analysis of cell apoptosis in OE-FOXO3a-tranfected cells. (B) Quantification of cell apoptosis from part (A). (C) Western blotting was used to analyze the protein expression levels of apoptosis-related molecules, Bcl-2, Bax, Bim, caspase-3/cleaved caspase-3 in OE-FOXO3a-transfected cells. ${ }^{* * *} \mathrm{P}<0.001$ vs. control; ${ }^{\# \# \# ~} \mathrm{P}<0.001$ vs. OE-NC; $\mathrm{n}=3$. FOXO3a, forkhead transcription factor O subfamily 3A; OE, overexpression; NC, negative control; Bim, Bcl-2-like protein 2.

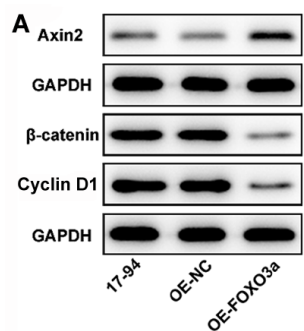

B

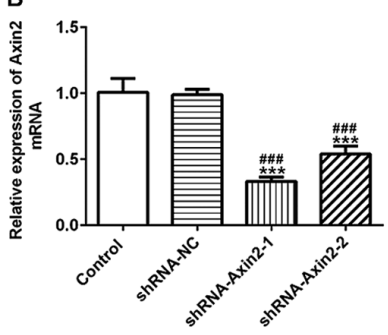

$E$

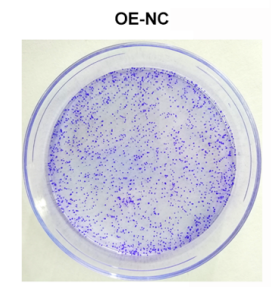

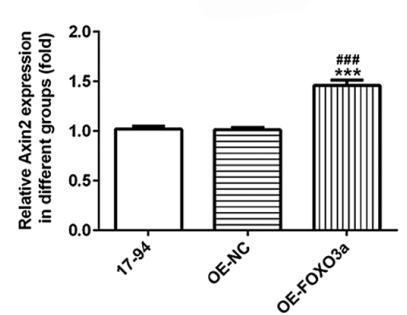

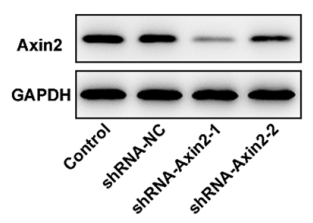

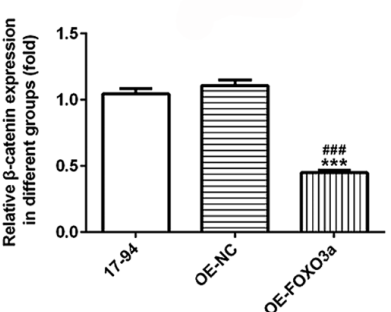

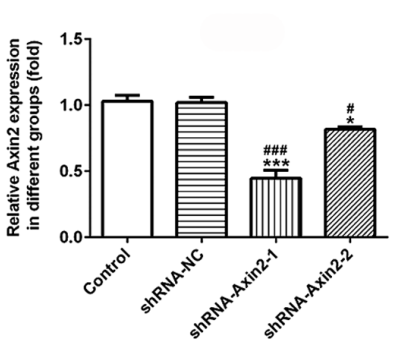

OE-FOXO3a

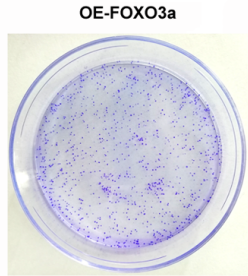

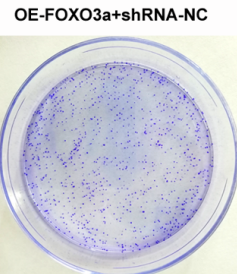

OE-FOXO3a+shRNA-Anxin2

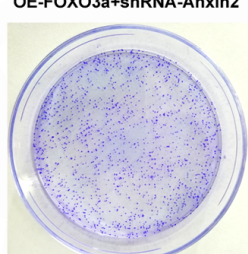

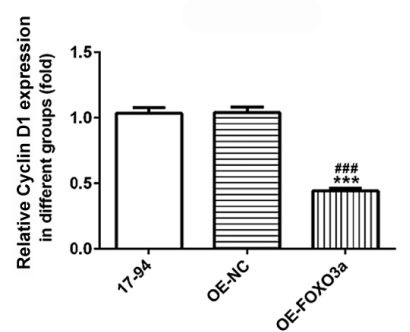

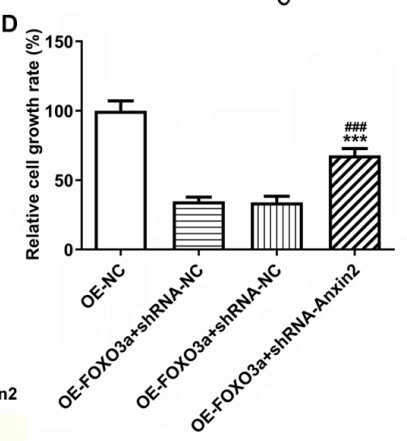

Figure 4. Activation of Wnt/ $\beta$-catenin signaling reverses FOXO3a overexpression-induced inhibition of the proliferation of nephroblastoma cells. (A) Western blotting was used to analyze the expression levels of the Wnt/ $\beta$-catenin signaling-related proteins, Axin- $2, \beta$-catenin and Cyclin D1. ${ }^{* * * *} \mathrm{P}<0.001$ vs. control; ${ }^{\# \#} \mathrm{P}<0.001 \mathrm{vs}$. OE-NC; $\mathrm{n}=3$. The transfection efficiency of shRNA-Axin-2-1 and shRNA-Axin-2-2 were detected using (B) reverse transcription-quantitative PCR and (C) western blotting. OE-FOXO3a and shRNA-Axin-2 were co-transfected into 17-94 cell lines and the cell viability and proliferation of 17-94 cells was detected using a (D) Cell Counting Kit-8 assay and (E) colony formation assay, respectively. ${ }^{*} \mathrm{P}<0.05,{ }^{* * * *} \mathrm{P}<0.001$ vs. control; ${ }^{\mathrm{P}} \mathrm{P}<0.05$, ${ }^{, \# \#} \mathrm{P}<0.001$ vs. shRNA-NC; $\mathrm{n}=3$. FOXO3a, forkhead transcription factor O subfamily $3 \mathrm{~A}$; OE, overexpression; $\mathrm{NC}$, negative control; OD, optical density; shRNA, short hairpin RNA. 
A

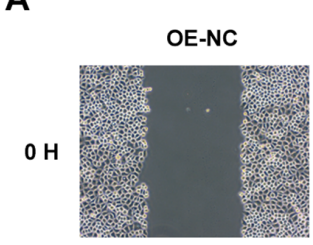

$24 \mathrm{H}$

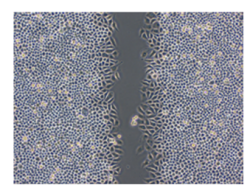

C

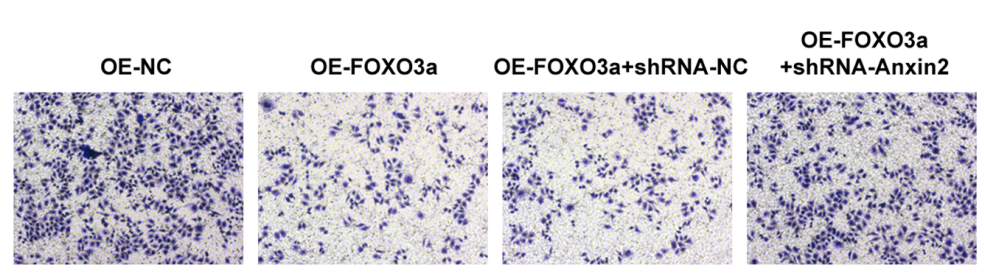

E
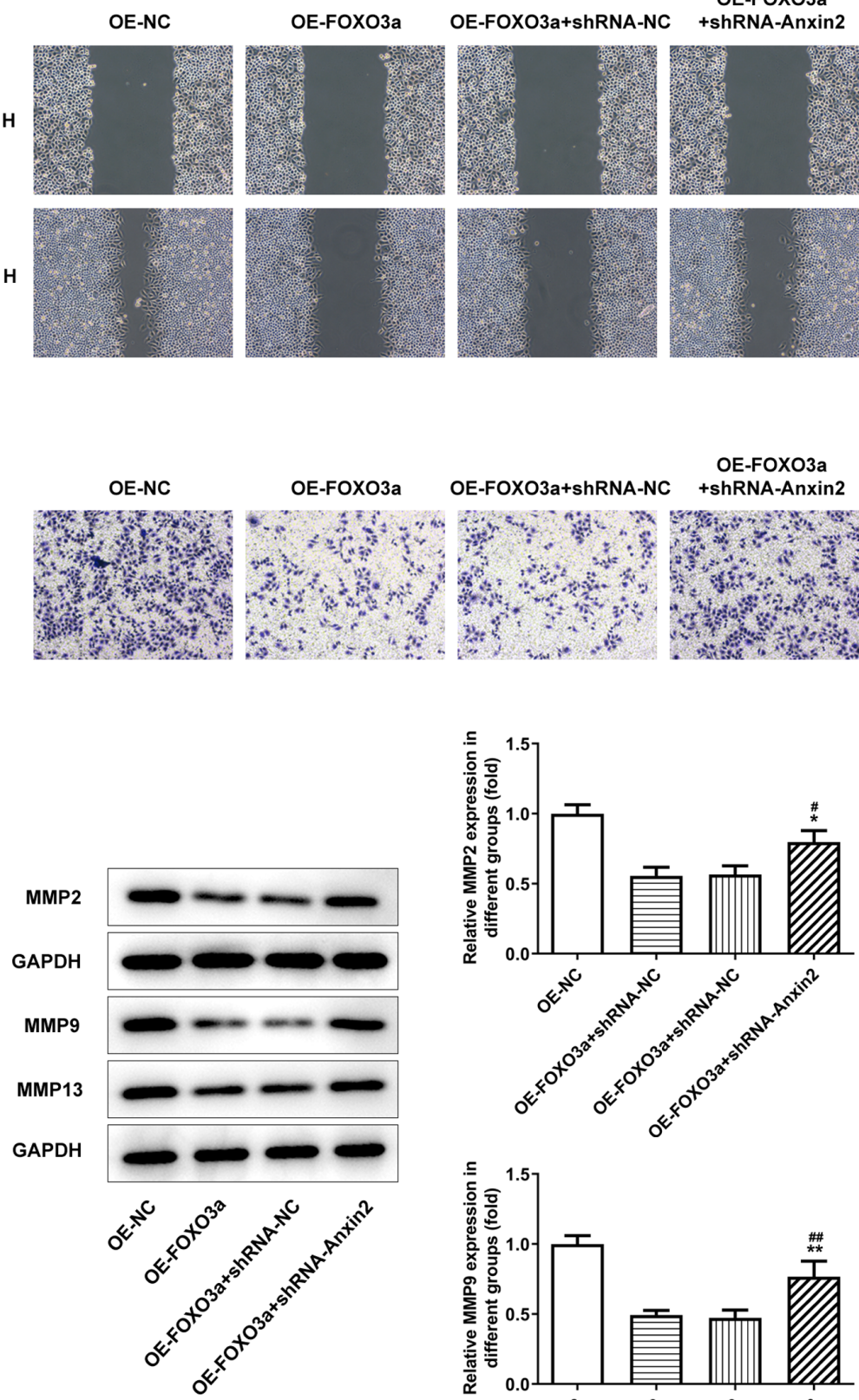

OE-FOXO3a
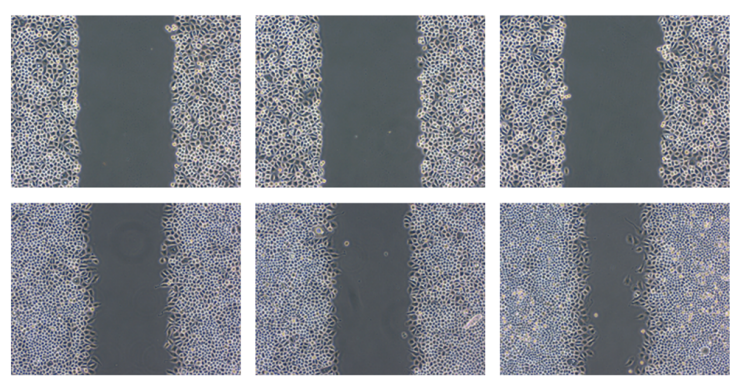

B
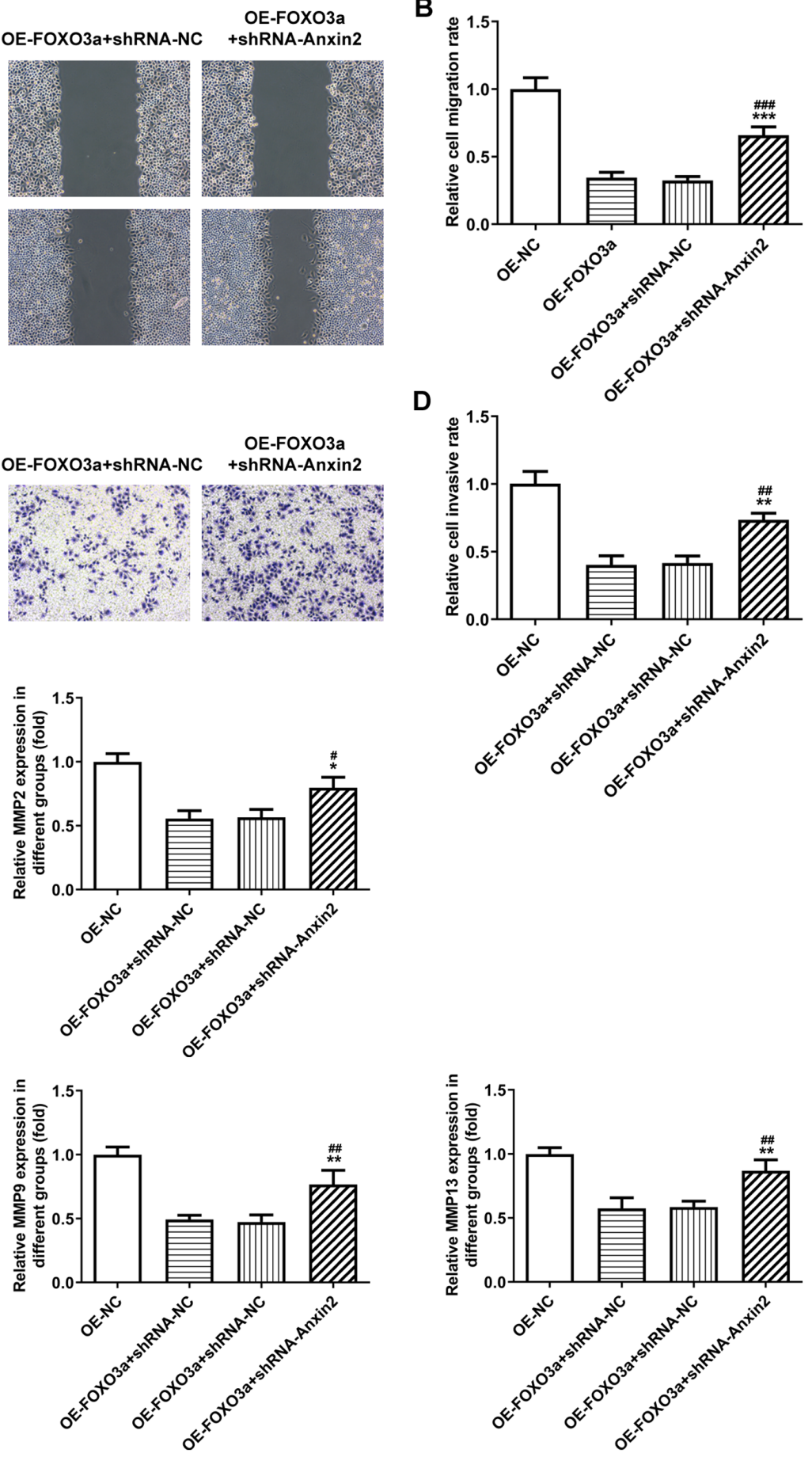

Figure 5. Activation of Wnt/ $\beta$-catenin signaling reverses FOXO3a overexpression-induced inhibition of the invasion and migration of nephroblastoma cells. (A) Wound healing assay was used to analyze the migratory ability of cells transfected with OE-FOXO3a + shRNA-Axin-2 (magnification, x200). (B) Semi-quantification of the cell migration rate from part (A). (C) Transwell Matrigel assay was used to analyze the invasive ability of cells transfected with OE-FOXO3a + shRNA-Axin-2 (magnification, x200). (D) Semi-quantification of the cell invasive rate from part (C). (E) Western blotting was performed to analyze the protein expression levels of MMP2, MMP9 and MMP13 in cells transfected with OE-FOXO3a + shRNA-Axin-2. ${ }^{*} \mathrm{P}<0.05,{ }^{* *} \mathrm{P}<0.01$, ${ }^{* * * *} \mathrm{P}<0.001$ vs. OE-FOXO3a; ${ }^{*} \mathrm{P}<0.05,{ }^{\# \prime} \mathrm{P}<0.01,{ }^{\# \# \#} \mathrm{P}<0.001$ vs. OE-FOXO3a + shRNA-NC; $\mathrm{n}=3$. FOXO3a, forkhead transcription factor O subfamily $3 \mathrm{~A}$; OE, overexpression; NC, negative control; shRNA, short hairpin RNA; MMP, matrix metalloproteinase.

tumor cells by regulating the expression of cell cycle-related factors and apoptosis-related factors effect $(40,41)$. In the present study, FOXO3a expression levels were discovered to be downregulated in nephroblastoma cell lines, suggesting that FOXO3a may serve an essential role in nephroblastoma. Furthermore, the results revealed that the overexpression of FOXO3a significantly attenuated nephroblastoma cell proliferative, migratory and invasive abilities. In addition, the overexpression of FOXO3a promoted the apoptosis of nephroblastoma cells. A previous study suggested that FOXO3a may be a potential biomarker for the diagnosis, prognosis and treatment of a variety of types of malignant tumor, including ovarian, prostate and pancreatic cancers $(42,43)$. Similarly, previous studies also reported that FOXO3a expression 
A

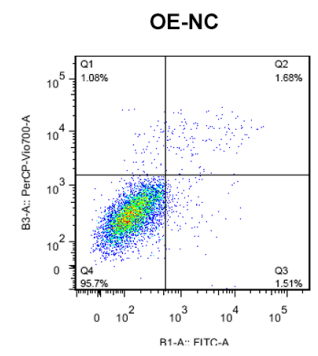

B
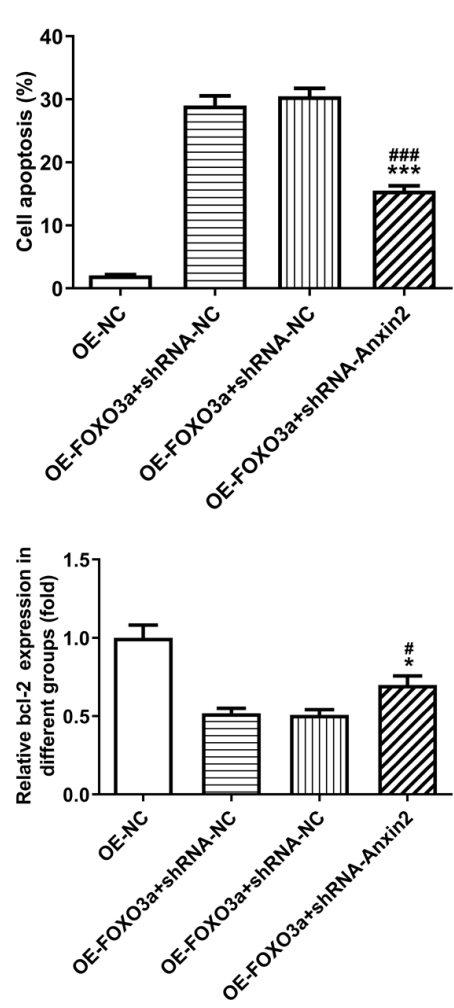

OE-FOXO3a

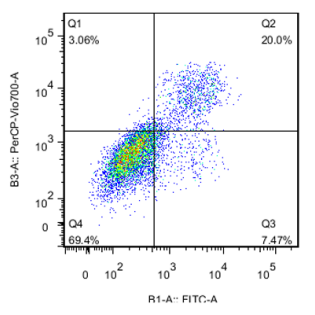

C
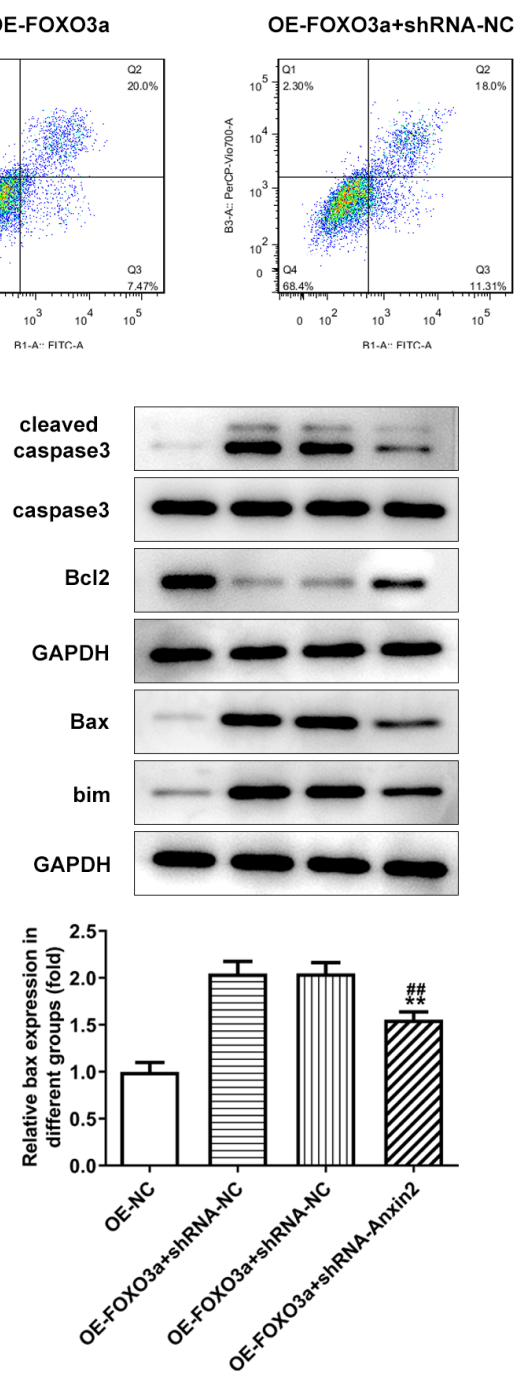

OE-FOXO3a+shRNA-Anxin2
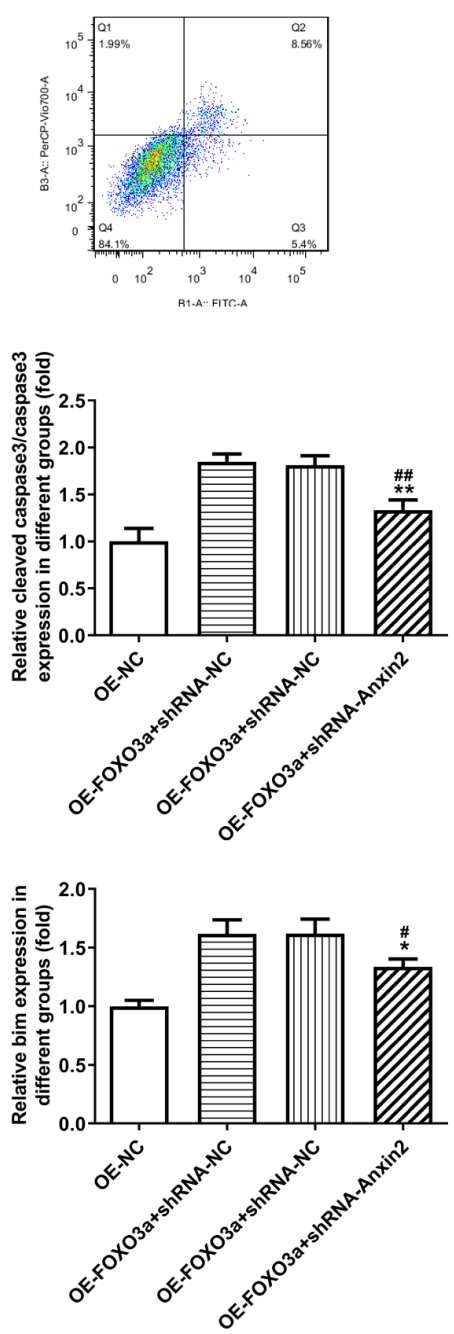

Figure 6. Activation of Wnt/ $\beta$-catenin signaling reverses the FOXO3a overexpression-induced apoptosis of nephroblastoma cells. (A) Flow cytometric analysis of cell apoptosis in cells transfected with OE-FOXO3a + shRNA-Axin-2. (B) Quantification of cell apoptosis from part (A). (C) Western blotting was used to analyze the protein expression levels of the apoptosis-related molecules, Bcl-2, Bax, Bim, caspase-3/ cleaved caspase-3. "P $<0.05$, ${ }^{* *} \mathrm{P}<0.01$, ${ }^{* * * *} \mathrm{P}<0.001$ vs. OE-FOXO3a; ${ }^{\# \mathrm{P}}<0.05,{ }^{\# \#} \mathrm{P}<0.01,{ }^{\# \# \#} \mathrm{P}<0.001$ vs. OE-FOXO3a + shRNA-NC, $\mathrm{n}=3$. FOXO3a, forkhead transcription factor $\mathrm{O}$ subfamily $3 \mathrm{~A}$; OE, overexpression; NC, negative control; shRNA, short hairpin RNA; Bim, Bcl-2-like protein 2.

levels could be used as a prognostic biomarker for clear cell renal cell carcinoma, cervical carcinoma and colorectal cancer $(14,29,42)$. Interestingly, the overexpression of FOXO3a has been associated with the poor prognosis of patients with triple negative breast cancer, glioblastoma and gastric cancer, while downregulated expression levels of FOXO3a were associated with the poor prognosis of patients with glioma and ovarian cancer (44-45). Therefore, these studies suggested that FOXO3a may be a potential biomarker for the diagnosis of nephroblastoma, and may potentially serve as an oncogene or suppressor factor to be investigated in relation to nephroblastoma progression, which requires further investigations. Based on these previous studies (46-50) and the present data, FOXO3a was hypothesized to be a potential molecular target for nephroblastoma therapy and diagnosis.

The Wnt/ $\beta$-catenin signaling pathway is an important signaling pathway involved in regulating cell proliferation and differentiation, and serves a crucial role in tumor development, metastasis and embryonic development $(23,24)$. In addition, it was reported that the $\mathrm{Wnt} / \beta$-catenin signaling pathway was highly activated in various types of cancer, such as ovarian epithelial cancer and prostate cancer $(51,52)$, thus, the inhibition of this signaling pathway has become a research hotspot. A previous study revealed that the inhibition of the Wnt/ $\beta$-catenin signaling pathway inhibited growth and promoted apoptosis in ovarian cancer cells (53), while microRNA-218 promoted the apoptosis of ovarian cancercells by inhibiting the Wnt/ $\beta$-catenin signaling pathway (53). In addition, lysyl oxidase homolog 2, a member of the lysyl oxidase family, was suggested to affect the growth of ovarian cancer cells by inhibiting the Wnt/ $\beta$-catenin signaling pathway (54). Thus, to further determine the possible mechanisms by which FOXO3a participated in nephroblastoma, the relationship between FOXO3a and the Wnt// $\beta$-catenin signaling pathway in nephroblastoma cells was investigated. The present study detected the expression of WNT/ $\beta$-catenin signaling proteins Axin2, $\beta$-catenin and cyclin D1. Following overexpression of FOXO3a, the expression of Axin2 increased significantly, and the expression of $\beta$-catenin and cyclin D1 
decreased significantly. Following co-transfection with shRNA-Axin-2, WNT signaling was activated, the activation of the Wnt/ $\beta$-catenin signaling pathway reversed the FOXO3a overexpression-induced suppression of proliferation, invasion and migration in nephroblastoma cells, in addition to reversing the FOXO3a-induced apoptosis of nephroblastoma cells.

In conclusion, the findings of the present study suggested that FOXO3a may inhibit nephroblastoma cell proliferation, invasion and migration, while inducing apoptosis through downregulating the Wnt/ $\beta$-catenin signaling pathway. These results may provide a novel method for the early diagnosis and treatment of nephroblastoma. A limitation of the present study was that FOXO3a was only studied in a nephroblastoma cell line; its application in vivo and in clinic was not studied but will be investigated in the future.

\section{Acknowledgements}

Not applicable.

\section{Funding}

No funding was received.

\section{Availability of data and materials}

The datasets used and/or analyzed during the current study are available from the corresponding author on reasonable request.

\section{Authors' contributions}

QL designed the study, collected the data, performed the data analysis and wrote the manuscript. CQ conceived the study, participated in designing the study and revised the manuscript. All authors read and approved the final manuscript.

\section{Ethics approval and consent to participate}

Not applicable.

\section{Patient consent for publication}

Not applicable.

\section{Competing interests}

The authors declare that they have no competing interests.

\section{References}

1. Leslie SW, Sajjad H and Murphy PB: Wilms Tumor (Nephroblastoma). StatPearls, Treasure Island, FL, 2019.

2. Anderson TE and Conran RM: Educational case: Wilms tumor (Nephroblastoma). Acad Pathol 6: 2374289518821381, 2019.

3. Zhang L, Gao X, Zhou X, Qin Z, Wang Y, Li R, Tang M, Wang W and Zhang W: Identification of key genes and microRNAs involved in kidney wilms tumor by integrated bioinformatics analysis. Exp Ther Med 18: 2554-2564, 2019.

4. Chakumatha E, Weijers J, Banda K, Bailey S, Molyneux E, Chagaluka and Israels T: Outcome at the end of treatment of patients with common and curable childhood cancer types in Blantyre, Malawi. Pediatr Blood Cancer 67: e28322, 2020.
5. Lamb MG, Aldrink JH, O'Brien SH, Yin H, Arnold MA and Ranalli MA: Renal tumors in children younger than 12 months of Age: A 65-year single institution review. J Pediatr Hematol Oncol 39: 103-107, 2017.

6. Illhardt T, Ebinger M, Schwarze CP,Feuchtinger T, Furtwangler R, Schlegel PG, Klingebiel T, Greil J, Beck JF, Handgretinger R and Lang P: Children with relapsed or refractory nephroblastoma: Favorable long-term survival after high-dose chemotherapy and autologous stem cell transplantation. Klin Padiatr 226: 351-356, 2014.

7. Weirich A, Ludwig R, Graf N, Abel U, Leuschner I, Vujanic GM, Mehls O, Boos J, Beck J, Royer-Pokora B and Voûte PA: Survival in nephroblastoma treated according to the trial and study SIOP-9/GPOH with respect to relapse and morbidity. Ann Oncol 15: 808-820, 2004.

8. Shi C, Shi R, Guo H, Shi Y and Liu X: $\beta$-amyloid-induced gonadotropin-releasing hormone decline involving forkhead transcription factor FOXO3a and nuclear factor- $\kappa \mathrm{B}$. Neuroreport 31: 923-927, 2020

9. Li Q, Tang H, Hu F and Qin C: Silencing of FOXO6 inhibits the proliferation, invasion, and glycolysis in colorectal cancer cells. J Cell Biochem 120: 3853-3860, 2019.

10. Menghini R, Casagrande V, Iuliani G, Rizza S, Mavilio M, Cardellini M and Federici M: Metabolic aspects of cardiovascular diseases: Is FoxO1 a player or a target? Int J Biochem Cell Biol 118: 105659, 2020.

11. Liu W, Li Y and Luo B: Current perspective on the regulation of FOXO4 and its role in disease progression. Cell Mol Life Sci 7: 651-663, 2019.

12. Usami M, Kikuchi S, Takada K, Ono M, Sugama Y, Arihara Y, Hayasaka N, Nakamura H, Ikeda Y, Hirakawa M, et al: FOXO3a activation by HDAC class IIa inhibition induces cell cycle arrest in pancreatic cancer cells. Pancreas 49: 135-142, 2020.

13. Belguise K, Guo S and Sonenshein GE: Activation of FOXO3a by the green tea polyphenol epigallocatechin-3-gallate induces estrogen receptor alpha expression reversing invasive phenotype of breast cancer cells. Cancer Res 67: 5763-5770, 2007.

14. Wu K, Fan J, Zhang L, Ning Z, Zeng J, Zhou J, Li L, Chen Y, Zhang T, Wang X, et al: PI3K/Akt to GSK3beta/beta-catenin signaling cascade coordinates cell colonization for bladder cancer bone metastasis through regulating ZEB1 transcription. Cell Signal 24: 2273-2282, 2012.

15. Ni D, Ma X, Li HZ, Gao Y, Li XT, Zhang Y, Ai Q, Zhang P, Song EL, Huang QB, et al: Downregulation of FOXO3a promotes tumor metastasis and is associated with metastasis-free survival of patients with clear cell renal cell carcinoma. Clin Cancer Res 20: 1779-1790, 2014.

16. Ramis G, Villalonga-Planells R, Serra-Sitjar M, Brell M, Fernandez de Mattos S and Villalonga P: The tumor suppressor FOXO3a mediates the response to EGFR inhibition in glioblastoma cells. Cell Oncol (Dordr) 42: 521-536, 2019.

17. Li J, Yang R, Dong Y, Chen M, Wang Y and Wang G: Knockdown of FOXO3a induces epithelial-mesenchymal transition and promotes metastasis of pancreatic ductal adenocarcinoma by activation of the $\beta$-catenin/TCF4 pathway through SPRY2. J Exp Clin Cancer Res 38: 38, 2019.

18. Chen H, Xu L and Wang L: Expression of miR-182 and Foxo3a in patients with bladder cancer correlate with prognosis. Int J Clin Exp Pathol 12: 4193-4203, 2019.

19. Zhao R, Li Y, Gorantla S, Poluektova LY, Lin H, Gao F, Wang H, Zhao J, Zheng JC and Huang Y: Small molecule ONC201 inhibits HIV-1 replication in macrophages via FOXO3a and TRAIL. Antiviral Res 168: 134-145, 2019.

20. Zhao W, Li J, Li P, Guo F, Gao P, Zhang J, Yan Z, Wang L, Zhang D and Qin P: Wilms tumor-suppressing peptide inhibits proliferation and induces apoptosis of Wilms tumor cells in vitro and in vivo. J Cancer Res Clin Oncol 145: 2457-2468, 2019.

21. Nitulescu GM, Van De Venter M, Nitulescu G, Ungurianu A, Juzenas P, Peng Q, Olaru OT, Grădinaru D, Tsatsakis A, Tsoukalas D, et al: The Akt pathway in oncology therapy and beyond (Review). Int J Oncol 53: 2319-2331, 2018.

22. Lachmandas E, Beigier-Bompadre M, Cheng SC, Kumar V, van Laarhoven A, Wang X, Ammerdorffer A, Boutens L, de Jong D, Kanneganti TD, et al: Rewiring cellular metabolism via the AKT/mTOR pathway contributes to host defence against Mycobacterium tuberculosis in human and murine cells. Eur J Immunol 46: 2574-2586, 2016.

23. Qian J, Huang X, Zhang Y, Ye X and Qian W: $\gamma$-catenin overexpression in AML patients may promote tumor cell survival via activation of the wnt/beta-catenin axis. Onco Targets Ther 13: 1265-1276, 2020 
24. Xiao Q, Wu J, Wang WJ, Chen S, Zheng Y, Yu X, Meeth K, Sahraei M, Bothwell AL, Chen L, et al: DKK2 imparts tumor immunity evasion through beta-catenin-independent suppression of cytotoxic immune-cell activation. Nat Med 24: 262-270, 2018

25. Anton R, Chatterjee SS, Simundza J, Cowin P and Dasgupta R: A systematic screen for micro-RNAs regulating the canonical wnt pathway. PLoS One 6: e26257, 2011.

26. Re GG, Hazen-Martin DJ, Sens DA and Garvin AJ: Nephroblastoma (Wilms' tumor): A model system of aberrant renal development. Semin Diagn Pathol 11: 126-135, 1994.

27. Hu Z, Li L, Cheng P, Liu Q, Zheng X, Peng F and Zhang Q: IncRNA MSC-AS1 activates Wnt/ $\beta$-catenin signaling pathway to modulate cell proliferation and migration in kidney renal clear cell carcinoma via miR-3924/WNT5A. J Cell Biochem 121: 4085-4093, 2020

28. Rim EY, Kinney LK and Nusse R: $\beta$-catenin-mediated wnt signal transduction proceeds through an endocytosis-independent mechanism. Mol Biol Cell 31: 1425-1436, 2020.

29. Haque I, Banerjee S, Mehta S, De A, Majumder M, Mayo MS, Kambhampati S, Campbell DR and Banerjee SK: Cysteine-rich 61-connective tissue grow th factor-nephroblastoma-overexpressed 5 (CCN5)/Wnt-1-induced signaling protein-2 (WISP-2) regulates microRNA-10b via hypoxia-inducible factor- $1 \alpha$-TWIST signaling networks in human breast cancer cells. J Biol Chem 286: 43475-43485, 2011.

30. Livak KJ and Schmittgen TD: Analysis of relative gene expression data using real-time quantitative PCR and the 2(-Delta Delta C(T)) method. Methods 25: 402-408, 2001.

31. Fair D, Potter SL and Venkatramani R: Challenges and solutions to the study of rare childhood tumors. Curr Opin Pediatr 32 7-12, 2020.

32. Chong WC and Cain JE: Lessons learned from the developmental origins of childhood renal cancer. Anat Rec (Hoboken) 303: 2561-2577, 2020

33. Hang S, Wang X and Li H: Triptolide inhibits viability and migration while promotes apoptosis in nephroblastoma cells by regulation of miR-193b-3p. Exp Mol Pathol 108: 80-88, 2019.

34. Liu H, Ren SY, Qu Y, Liu C, Zhang Y, Li XQ and Ma H: MiR-194-5p inhibited metastasis and EMT of nephroblastoma cells through targeting Crk. Kaohsiung J Med Sci 36: 265-273, 2019.

35. Nakabayashi A, Kanno T, Takahashi N, Akizawa Y, Onizuka H and Matsui H: A case of ovarian teratoma with nephroblastoma presenting spontaneous rupture. J Obstet Gynaecol Res 45: 1079-1083, 2019

36. Bellalah A, Abdeljelil NB, Njima M, Hamdani M, Hamdouni W, Hadhri R, Moussa A, Zakhama A and Njim L: Fetal rhabdomyomatous nephroblastoma in a 31-year-old woman: A case report. Urology 133: e5-e6, 2019.

37. HuY and YanJ:AberrantexpressionandmechanismofmiR-130b-3p/ phosphatase and tensin homolog in nephroblastoma in children. Exp Ther Med 18: 1021-1028, 2019.

38. Jones BC, Youlden DR, Cundy TP, O'Callaghan ME, Karpelowsky J, Aitken JF and Mcbride CA: Renal tumours in Australian children: 30 years of incidence, outcome and second primary malignancy data from the Australian childhood cancer registry. J Paediatr Child Health 56: 908-916, 2020.

39. Pomponio MK, Burkbauer L, Goldbach M, Nazarian SM, Xie F, Clark AS, Matro JM, Fox KR, Shulman LN, Keele LJ and Tchou J: Refining the indications for neoadjuvant chemotherapy for patients with HER2+ breast cancer: A single institution experience. J Surg Oncol 121: 447-455, 2020.
40. Wang X, Su D, Qin Z and Chen Z: Identification of FOXN4 as a tumor suppressor of breast carcinogenesis via the activation of TP53 and deactivation of notch signaling. Gene 722: 144057, 2020.

41. Strassheim D, Karoor V, Nijmeh H, Weston P, Lapel M, Schaack J, Sullivan T, Dempsey EC, Stenmark KR and Gerasimovskaya E: c-Jun, Foxo3a, and c-Myc transcription factors are key regulators of ATP-mediated angiogenic responses in pulmonary artery vasa vasorum endothelial cells. Cells 9: 416, 2020.

42. Grossi V, Fasano C, Celestini V, Signorile ML, Sanese P and Simone C: Chasing the FOXO3: Insights into its new mitochondrial lair in colorectal cancer landscape. Cancers (Basel) 11: 414, 2019.

43. Vasickova K, Horak P and Vanhara P: TUSC 3 : functional duality of a cancer gene. Cell Mol Life Sci 75: 849-857, 2018

44. Yue X, Zhang C, Zhao Y, Liu J, Lin AW, Tan VM, Drake JM, Liu L, Boateng MN, Li J, et al: Gain-of-function mutant p53 activates small GTPase Rac1 through SUMOylation to promote tumor progression. Genes Dev 31: 1641-1654, 2017.

45. Pang X, Zhou Z, Yu Z, Han L, Lin Z, Ao X, Liu C, He Y, Ponnusamy M, Li P and Wang J: Foxo3a-dependent miR-633 regulates chemotherapeutic sensitivity in gastric cancer by targeting fas-associated death domain. RNA Biol 16: 233-248, 2019.

46. Ge YF, Sun J, Jin CJ, Cao BQ, Jiang ZF and Shao JF: AntagomiR-27a targets FOXO3a in glioblastoma and suppresses U87 cell growth in vitro and in vivo. Asian Pac J Cancer Prev 14: 963-968, 2013.

47. Liu H, Song Y, Qiu H, Liu Y, Luo K, Yi Y, Jiang G, Lu M, Zhang Z, Yin J, et al: Downregulation of FOXO3a by DNMT1 promotes breast cancer stem cell properties and tumorigenesis. Cell Death Differ 27: 966-983, 2020

48. Jin L, Zhang J, Fu HQ, Zhang X and Pan YL: FOXO3a inhibits the EMT and metastasis of breast cancer by regulating TWIST-1 mediated miR-10b/CADM2 axis. Transl Oncol 14: 101096, 2021.

49. Huang X, Chen Z, Shi W, Zhang R, Li L, Liu H and Wu L: TMF inhibits miR-29a/Wnt/ $\beta$-catenin signaling through upregulating Foxo3a activity in osteoarthritis chondrocytes. Drug Des Devel Ther 13: 2009-2019, 2019.

50. Sun T, Zhang J, Deng B, Fan X, Long T, Jin H, Tao S, Kang P, Tan Q: FOXO1 and FOXO3a sensitize non-small-cell lung cancer cells to cisplatin-induced apoptosis independent of Bim. Acta Biochim Biophys Sin 52: 1348-1359, 2020.

51. Zhu Z, Zhang H, Lang F, Liu G, Gao S, Li B and Liu Y: Pin1 promotes prostate cancer cell proliferation and migration through activation of Wnt/beta-catenin signaling. Clin Transl Oncol 18: 792-797, 2016.

52. Kotrbova A, Ovesna P, Gybel T,Radaszkiewicz T,Bednaříková M, Hausnerová J, Jandáková E, Minář L, Crha I, Weinberger V, et al: WNT signaling inducing activity in ascites predicts poor outcome in ovarian cancer. Theranostics 10: 537-552, 2020.

53. Huang Y, Liang SH, Xiang LB, Han XT, Zhang W, Tang J, Wu XH and Zhan MQ: miR-218 promoted the apoptosis of human ovarian carcinoma cells via suppression of the WNT/beta-catenin signaling pathway. Mol Biol (Mosk) 51: 629-636, 2017 (In Russian).

54. Han XF, Zhang XX, Liu KM and Zhang Q: Apelin-13 deficiency alters cortical bone geometry, organic bone matrix, and inhibits Wnt $/ \beta$-catenin signaling. Gen Comp Endocrinol 267: 29-35, 2018.

This work is licensed under a Creative Commons Attribution-NonCommercial-NoDerivatives 4.0 International (CC BY-NC-ND 4.0) License. 